\title{
INFLUÊNCIA DAS INOVAÇÕES TECNOLÓGICAS EM UNIDADES DE PRODUÇÃO FAMILIARES DA REGIÃO OESTE DE SANTA CATARINA ${ }^{1}$
}

\author{
Flávio José Simioni² \\ Teisonara Celine Zilliotto ${ }^{3}$
}

RESUMO: O objetivo neste trabalho foi avaliar quais variáveis são determinantes para a incorporação de inovações tecnológicas em propriedades rurais familiares, assim como identificar as características das tecnologias empregadas e seus impactos. A pesquisa foi desenvolvida na região oeste catarinense, utilizando-se de um questionário para a coleta de dados em 59 propriedades rurais familiares. As propriedades rurais foram classificadas em três grupos, segundo o número e características das inovações tecnológicas empregadas. Os dados foram submetidos à análise estatística multivariada, utilizando a Principal Component Analysis (PCA). A renda bruta obtida com atividades pecuárias (Renda Pecuária) e a obtida com atividades agrícolas (Renda Agrícola) foram as variáveis respostas utilizadas nas análises. Como variáveis explicativas foram consideradas a idade e a escolaridade do produtor, capital de exploração, área de terra, associação em cooperativas, acesso à internet, uso de crédito, unidades de trabalho familiar e as rendas não agrícolas. Os resultados indicam que as unidades de produção que apresentam maior renda agrícola e pecuária, associadas à maior disponibilidade de terra, de capital investido na propriedade e grau de escolaridade do gestor mais elevado são as mais inovadoras, enquanto aquelas que apresentam baixo grau de inovação estão vinculadas ao desenvolvimento de atividades não agrícolas.

Palavras-chave: Tecnologia. Renda. Agricultura familiar.

1 Recebido em: 07/08/2013. Aceito em: 02/09/2013.

2 Professor Doutor do Departamento de Zootecnia. Universidade do Estado de Santa Catarina- UDESC. E-mail: flavio.simioni@udesc.br

3 Bolsista de Iniciação Científica do Departamento de Zootecnia. Universidade do Estado de Santa CatarinaUDESC. E-mail: teisonara@hotmail.com 


\begin{abstract}
The aims of this study were to assess which variables are crucial for the incorporation of technological innovations in family farms, and identify the characteristics of the technologies employed and their impacts. The survey was conducted in western Santa Catarina, using a questionnaire to collect data on 59 family farms. The farms were classified into three groups according to the number and characteristics of the technological innovations employed. Data were statistically analyzed using multivariate Principal Component Analysis (PCA). The gross income obtained from farming activities (Income Breeding) and obtained with agricultural activities (Agriculture Income) were the response variables used in the analyzes. The explanatory variables considered were age and educational level the producer, working capital, land area, membership in cooperatives, internet access, use of credit, units of family labor and non-agricultural incomes. The results indicate that the farms with higher farm income and breeding, associated with greater availability of land area, the property capital and high education of gesture are the most innovative, while those that present low level of innovation are linked to the development of activities non-agricultural.
\end{abstract}

Keywords: Technology. Income. Family farming.

\title{
1. Introdução
}

É amplamente reconhecida a importância das inovações tecnológicas no aumento da produtividade dos fatores de produção, principalmente na produtividade do trabalho. A introdução de tecnologias agropecuárias com impactos na produtividade teve início há muitos anos, porém centradas em algumas culturas e geograficamente concentrada. Um esforço mais amplo de difusão começou a ser feito apenas a partir da década de 1960, com o advento da modernização da agricultura - a chamada "Revolução Verde".

Utilizando-se da abordagem do processo de treadmil descrito por Chochrane (1958), Veiga (1992) demonstra que a adoção de inovações tecnológicas pelos produtores inovadores proporciona aumento da eficiência produtiva, gerando lucro extraordinário, dado que a oferta e preços de mercado permanecem inalterados. Contudo, na medida em que a tecnologia se difunde a um número maior de produtores, a oferta de mercado é ampliada e os preços caem, levando novamente ao lucro 
normal no longo prazo. Já os produtores que não inovam (retardatários) são levados à exclusão pela crescente redução de sua lucratividade. Neste cenário, torna-se imperativo a constante inovação para garantir a permanência na atividade.

Nesta perspectiva, com o objetivo de verificar o efeito da incorporação de tecnologias, Conterato et al. (2012) analisaram a eficiência produtiva da agricultura brasileira através da Produtividade Total dos Fatores (PTF), que aumentou 3,7 vezes no período de 1975 a 2010, porém o incremento maior se deu após 1995. Este, entre outros fatores, corroborou a queda real dos preços em dólar das commodities no Brasil, na ordem de 75\% (BARROS, 2010).

O aumento da escala e a concentração da produção são movimentos que vêm ocorrendo na agricultura brasileira. Como exemplo, o número de estabelecimentos agropecuários em Santa Catarina, que produziam leite, passou de mais de 145,7 mil no ano de 1995/96 para aproximadamente 89 mil produtores em 2006 (-38,9\%), enquanto a produção de leite no mesmo período passou de 870 milhões de litros para 1.394 milhões de litros, correspondendo a um acréscimo de mais de 60\% (IBGE, 2013).

Considerando os efeitos associados à incorporação de tecnologias no meio rural e pelo fato de o espaço agrário ser caracterizado pela sua diversidade de tipos de agricultores e heterogeneidade no uso de tecnologias (LIMA et al. 2001), torna-se importante conhecer as diferentes realidades para a proposição de políticas adequadas para atender as necessidades locais para que elas produzam resultados efetivos.

Assim, o objetivo deste trabalho foi analisar quais variáveis são determinantes para a incorporação de inovações tecnológicas em propriedades rurais familiares, assim como identificar as características das tecnologias empregadas e seus impactos provocados sobre o ambiente em que foi inserida. A ideia é compreender, sob o ponto de vista dos agricultores, de que forma as inovações tecnológicas contribuem para melhoria das condições de vida e geração de renda da família. 


\section{Metodologia}

Esta pesquisa foi desenvolvida na mesorregião Oeste de Santa Catarina, contemplando 59 unidades de produção (UP), distribuídas em 13 municípios representativos: Arvoredo (2), Água Doce (1), Águas de Chapecó (10), Chapecó (3), Faxinalzinho (1), Guatambu (1), Irani (2), Lageado Grande (3), Pinhalzinho (10), Rodeio Bonito (1), São Lourenço do Oeste (2), Vargem Bonita (12) e Xaxim (11). A amostra foi delimitada seguindo critérios de acessibilidade, saturação das fontes (ou exaustão) e surgimento de regularidades (MINAYO, 2008). Trata-se de uma amostra não probabilística, pois foi composta de forma autogerada, ou seja, foi iniciada pela indicação de potenciais entrevistados e cresceu sucessivamente por novas indicações (MATTAR, 2001).

A região foi escolhida pela predominância de pequenas unidades familiares de produção agrícola diversificada que, atualmente, detém o maior complexo agroindustrial de suínos e aves do Brasil. Sob o ponto de vista econômico, mais da metade do valor global da produção primária estadual é gerada nessa região (SILVA et al., 2003). De acordo com dados do Censo Agropecuário de 2006 (IBGE, 2013), a mesorregião possuía 82.143 estabelecimentos agropecuários, representando $42,4 \%$ do total catarinense.

O período de coleta dos dados foi entre os meses de dezembro de 2011 a março de 2012, considerando o ano de 2011 como referência. Utilizou-se de um questionário como instrumento para a coleta de dados, adotando a visita do pesquisador até às UPs como estratégia, onde os proprietários responderam o questionário. As UP são propriedades rurais familiares, contendo uma área média de 24 hectares, assim estratificadas: 17\% delas têm até 10 ha; $64 \%$, de 10 a 30 ha; e $19 \%$, acima de 30 ha. Atuam basicamente nas atividades de bovinocultura de leite, avicultura, grãos e suinocultura.

Inicialmente, as UPs foram classificadas em três grupos segundo o número e características das inovações empregadas nos anos de 2010 e 
2011, quais sejam:

1 Não Inovou (NI): UPs que não promoveram nenhuma inovação tecnológica nos anos de referência;

2 Baixa Inovação (BI): UPs que promoveram até duas inovações tecnológicas nos dois últimos anos, porém classificadas qualitativamente de baixa intensidade ou impacto sobre o sistema produtivo;

3 Alta Inovação (AI): UPs que promoveram até duas inovações tecnológicas nos dois últimos anos, classificadas qualitativamente de alta intensidade ou impacto sobre o sistema produtivo, ou promoveram três ou mais inovações tecnológicas nos dois últimos anos.

A Renda Pecuária, considerando o valor monetário das receitas brutas (R\$) provenientes de atividades pecuárias, e a Renda Agrícola, correspondendo ao valor monetário das receitas brutas $(\mathrm{R} \$)$ provenientes de atividades agrícolas e florestais, foram utilizadas como variáveis respostas para a separação dos grupos analisados.

As variáveis explicativas foram selecionadas considerando aquelas que mais influenciam a adoção de inovações tecnológicas nas UPs e interferem na renda dos produtores, conforme estudo de Souza Filho et al. (2011), contemplando as seguintes informações:

a) Cooperado: indica se o produtor rural é associado (cooperado) a alguma cooperativa. A variável é binária (dummy) e admite valor um para os produtores cooperados e zero para os não cooperados;

b) Internet: indica se o produtor rural tem acesso à internet. A variável é binária (dummy) e admite valor um para os produtores com acesso à internet e zero para os que não têm acesso;

c) Escolaridade: a variável é ordinal e foi organizada em quatro classes, 
considerando o nível de escolaridade do produtor (a) rural, principal gestor da UP: zero para analfabeto, um para os que têm ensino fundamental incompleto ou completo, dois para os que têm ensino médio incompleto ou completo e três para os que têm ensino superior incompleto ou completo;

d) Idade: considera a idade do produtor (a) rural, principal gestor da UP, medida em anos;

e) UTH F: refere-se à força de trabalho familiar das UPs, sendo uma UTH equivalente a 300 dias de trabalho, oito horas diárias de uma pessoa adulta entre 14 e 65 anos. Utilizou-se como critério para conversão da mão de obra 0,5 UTH para pessoas ativas com idade entre 10 a 14 anos, uma UTH para adultos de 14 a 65 correspondendo e 0,75 UTH para pessoas acima de 65 anos de idade (SOLDATELLI, 1992).

f) Capital: considera o valor de todo o capital investido na UP (R\$), exceto o valor da terra. Contempla a soma do valor das construções, máquinas, equipamentos, ferramentas, veículos, animais, culturas permanentes, entre outras;

g) Renda Não Agrícola (RNA): corresponde ao valor monetário das receitas brutas $(\mathrm{R} \$)$ provenientes de atividades não agrícolas;

g) Área: área total própria (ha) trabalhada ou explorada pela UP para a produção agropecuária; e

i) Crédito: corresponde ao valor total de recursos $(\mathrm{R} \$)$ obtidos em diferentes linhas de crédito.

Os dados foram submetidos a métodos de análise estatística multivariada. Inicialmente, utilizou-se da análise de Detrended Correspondence Analysis (DCA) para a obtenção do comprimento do gradiente. Como o comprimento do gradiente foi menor do que três $(1,160)$ significa que cada variável assume uma resposta linear em relação ao eixo (gradiente) (LEPS; SMILAUER, 1999). Neste caso, de acordo com os mesmos 
autores, indica-se o uso da Principal Component Analysis (PCA) para a separação dos grupos avaliados (NI, BI e AI). As variáveis explicativas foram adicionadas a posteriori para relacioná-las com as variáveis respostas, visualizando assim a estrutura subjacente dos dados. Todas as análises realizadas utilizaram-se do programa CANOCO versão 4.6 (TER BRAAK; SMILAUER, 1998).

Adicionalmente, foi identificada a principal inovação tecnológica empregada na propriedade em 2011, segundo a percepção do produtor. Para os grupos BI e AI, foram verificados o grau de influência sobre os custos de produção, a qualidade do produto, as práticas aplicadas e a rentabilidade da atividade que recebeu a tecnologia. Como parâmetro de mensuração, a influência foi classificada, segundo a visão dos produtores rurais, em baixa, média e alta, dependendo do impacto sobre cada variável.

Para entender o cenário em que as tecnologias são empregadas, verificou-se também a trajetória de incorporação de inovações nas UP pela identificação do número de inovações que ocorreram no último ano (2011), nos últimos dois anos (2010 e 2011) e nos últimos cinco anos (de 2007 a 2011). As duas principais atividades agropecuárias que receberam as inovações foram classificadas em baixo, médio e alto nível tecnológico, considerando a tecnologia empregada em relação à tecnologia disponível.

\section{Resultados e discussão}

Analisando-se o número médio de inovações tecnológicas empregadas na UP, verificou-se que os produtores rurais empregaram 1,43 inovações no último ano, 2,61 nos dois últimos anos e 4,61 quando considerados os últimos cinco anos. Entretanto, em termos absolutos, oito UPs não fizeram inovações em 2011 (Grupo NI), 33 efetivaram pequenas inovações (Grupo BI) e 18 UP são fortemente inovadoras (Grupo AI). A análise preliminar dos dados, considerando a participação percentual, média e o desvio padrão das variáveis respostas e explicativas, revela significativa 
variabilidade dificultando a separação entre os grupos avaliados. Contudo, algumas variáveis tais como a renda agrícola, capital e a obtenção de financiamentos fornecem indícios de que estão associadas à inovação tecnológicas nas UPs (Tabela 1).

Tabela 1 - Estatísticas descritivas das variáveis respostas e explicativas segundo o grau de inovação tecnológica das UP

\begin{tabular}{|c|c|c|c|c|}
\hline \multirow{2}{*}{ VARIÁVEL } & \multirow{2}{*}{ UNIDADE DE MEDIDA } & \multicolumn{3}{|c|}{ ESTATÍSTICA DESCRITIVA } \\
\hline & & NI (8) & BI (33) & AI (18) \\
\hline Área & Hectares $(\mu \pm \sigma)$ & $22,4 \pm 18,1$ & $17,9 \pm 14,0$ & $17,1 \pm 25,3$ \\
\hline Escolaridade* & $\begin{array}{l}0 \text { - Analfabeto }(\%) \\
\text { 1- Fundamental incompleto } \\
\text { e completo }(\%) \\
\text { 2- Médio completo }(\%) \\
\text { 3- Superior completo }(\%)\end{array}$ & $\begin{array}{l}12,5 \\
75,0 \\
12,5 \\
-\end{array}$ & $\begin{array}{l}3,0 \\
72,7 \\
18,2 \\
6,1\end{array}$ & $\begin{array}{l}- \\
77,8 \\
22,2 \\
-\end{array}$ \\
\hline Internet & $\operatorname{Sim}(\%)$ & 37,5 & 33,3 & 27,8 \\
\hline Cooperado & $\operatorname{Sim}(\%)$ & 87,5 & 84,8 & 88,9 \\
\hline Idade & $\operatorname{Anos}(\mu \pm \sigma)$ & $49,3 \pm 6,8$ & $47,7 \pm 10,5$ & $48,7 \pm 7,0$ \\
\hline UTH familiar & $\mathrm{UTH}(\mu \pm \sigma)$ & $3,0 \pm 1,7$ & $3,1 \pm 1,3$ & $3,5 \pm 1,2$ \\
\hline Capital & Mil R\$ $(\mu \pm \sigma)$ & $367,6 \pm 280,0$ & $566,2 \pm 732,1$ & $444,8 \pm 327,3$ \\
\hline Renda Pecuária & Mil R\$ $(\mu \pm \sigma)$ & $115,2 \pm 167,3$ & $111,1 \pm 122,9$ & $121,7 \pm 147,2$ \\
\hline Renda Agrícola & Mil $R \$(\mu \pm \sigma)$ & $9,9 \pm 10,9$ & $21,0 \pm 31,7$ & $12,9 \pm 9,7$ \\
\hline RNA & Mil R\$ $(\mu \pm \sigma)$ & $7,2 \pm 7,1$ & $13,2 \pm 18,0$ & $6,2 \pm 7,0$ \\
\hline Crédito & Mil R\$ $(\mu \pm \sigma)$ & $16,0 \pm 7,9$ & $52,3 \pm 47,8$ & $58,8 \pm 68,5$ \\
\hline
\end{tabular}

Fonte: Pesquisa de campo - dados trabalhados pelos autores.

Nota: Para a variável escolaridade, não foram encontrados dados de ensino médio e superior incompletos. 
A análise multivariada mostrou que os eixos um e dois da PCA para o grau de inovação tecnológica explicaram, respectivamente, 36,9 e $33,0 \%$ da variabilidade dos dados, enquanto o eixo três explicou $30,1 \%$. Assim, 69,9\% da variabilidade total dos dados foi explicada pelas duas primeiras dimensões.

O valor médio dos componentes principais representados pelos centroides da variável dependente (Inovação) mostra a nítida separação entre os três grupos avaliados (Figura 1). O triplot da PCA indica, através do eixo um, a separação dos produtores altamente inovadores (AI) dos que apresentam baixa inovação (BI). Pelo eixo dois, a separação do grupo AI em relação aos que não inovaram ou apresentaram alguma inovação (NI e BI) ficou mais explícita.

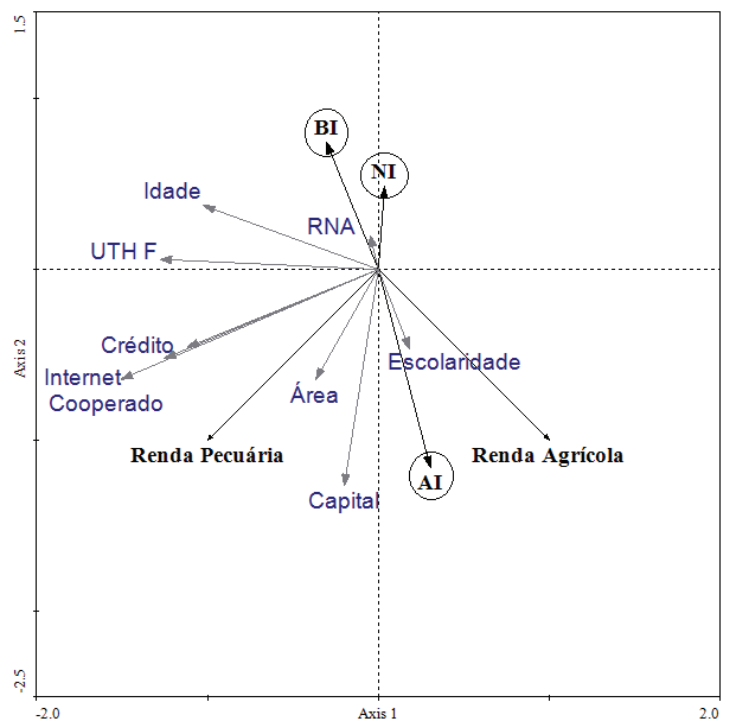

Figura 1 - Triplot das variáveis respostas e explicativas através da análise PCA no plano definido pelas dimensões um e dois e valor médio dos componentes principais representados pelos centroides dos grupos analisados 
De acordo com a Figura 1, o grupo de produtores inovadores (AI) está fortemente associado à obtenção de maior renda, principalmente agrícola, como também de origem pecuária. As variáveis que explicam este resultado são a maior disponibilidade de área de terra, o capital investido na UP e o nível de escolaridade mais elevado do produtor.

Ellis (2000) destaca que o acesso aos diferentes fatores de produção impacta o nível de renda e a qualidade de vida das famílias. Por sua vez, quanto maior o nível de rendimento, maior é a capacidade de ter acesso aos meios de sustento e de transformá-los em renda e qualidade de vida. A visão esclarece os resultados encontrados no presente trabalho, ou seja, as UPs que têm maior disponibilidade dos fatores de produção terra e capital auferem maior renda e possibilitam o acesso ao crédito e, consequentemente, a incorporação de inovações tecnológicas.

De acordo com Souza Filho et al. (2011), o papel desempenhado pelo tamanho da propriedade (área) na adoção de tecnologias depende de aspectos técnicos, econômicos e institucionais e está relacionado também com o acesso a créditos e financiamentos. Em geral, existe elevado grau de correlação entre tamanho da propriedade e outras variáveis, tais como condições de acesso ao crédito, grau de capitalização e participação em programas governamentais. Pereira et al. (2004) destacam que o crédito é fundamental para a compra de insumos e equipamentos necessários para produzir. Avaliando os impactos do Pronaf, Mattei (2005) e Guanziroli (2006) concluíram que a política pública de crédito permite que os agricultores familiares invistam em suas atividades e ampliem as áreas plantadas, resultando em aumento da produção total, do emprego e da arrecadação tributária.

O nível educacional pode ser um fator importante na adoção de novas tecnologias, relacionado não somente com a habilidade de obter e processar informações, mas também com o uso de técnicas de gestão. A escolaridade, juntamente com a experiência dos produtores, são características pessoais que determinam as decisões sobre a adoção destas práticas (SOUZA FILHO et al., 2011). Ney; Hoffmann (2003), com base 
nos dados da Pesquisa Nacional por Amostra de Domicílios (PNAD), concluíram que o capital físico é o principal fator que responde pelas desigualdades de renda no meio rural. A escolaridade também aparece com efeitos positivos sobre a produtividade do trabalho.

A explicação da forte associação do grupo AI com a obtenção de renda de origem agrícola e pecuária pode estar no perfil das atividades desenvolvidas pelos produtores, concentradas principalmente nas atividades de bovinocultura de leite, avicultura, suínos e produção de grãos (Tabela 2). A análise dos dados evidencia que a produção leiteira é a principal atividade em quase 58\% das UPs avaliadas, seguida da avicultura, com $27 \%$, constituindo o sistema Leite-Aves em $85 \%$ das UPs. Nos casos em que a avicultura é a principal atividade, o leite ocupa a segunda posição em termos de importância, evidenciando assim a vocação para a produção pecuária da região. Já as atividades de suinocultura, produção de grãos e outras atividades são desenvolvidas com menor importância como primeira atividade, porém com maior participação percentual como segunda atividade.

Tabela 2 - Principais atividades desenvolvidas nas UPs e correspondente nível tecnológico

\begin{tabular}{|c|c|c|c|c|c|c|c|c|c|}
\hline \multirow{2}{*}{$\begin{array}{l}\text { Primeira } \\
\text { Atividade }^{1)}\end{array}$} & \multirow{2}{*}{$\%$} & \multicolumn{3}{|c|}{ Nível Tecnológico } & \multirow{2}{*}{$\begin{array}{l}\text { Segunda } \\
\text { Atividade }^{2)}\end{array}$} & \multirow{2}{*}{$\%$} & \multicolumn{3}{|c|}{ Nível Tecnológico } \\
\hline & & Alto & Médio & Baixo & & & Alto & Médio & Baixo \\
\hline Leite & 57,6 & 7 & 25 & 2 & Aves & 30,4 & 2 & 12 & 1 \\
\hline Aves & 27,1 & 4 & 11 & 1 & Leite & 21,7 & 0 & 9 & 1 \\
\hline Suínos & 8,5 & 2 & 3 & 0 & Suínos & 15,2 & 1 & 6 & 2 \\
\hline Grãos & 1,7 & 0 & 1 & 0 & Grãos & 13,0 & 1 & 4 & 1 \\
\hline Outras & 5,1 & 0 & 3 & 0 & Outras & 19,6 & 1 & 3 & 2 \\
\hline Total & 100,0 & 13 & 43 & 3 & Total & 100,0 & 5 & 34 & 7 \\
\hline
\end{tabular}

Notas: 1) A primeira atividade é aquela considerada a mais importante pelo produtor e que mais contribui na formação da renda bruta total da propriedade. 2) A segunda atividade é aquela que ocupa a segunda posição na formação da renda bruta total da propriedade. 
De modo geral, o nível tecnológico empregado nas atividades é considerado médio, de acordo com os padrões empregados na região. Contudo, um nível tecnológico mais alto é verificado nas atividades que apresentam maior importância para a UP. De acordo com a Tabela 2, o nível tecnológico classificado como alto aparece com maior frequência nas atividades que ocupam a primeira posição quanto à importância na formação da renda.

Quando se analisa a principal inovação tecnológica empregada nas UP, percebe-se que, tanto para o grupo BI como para AI, as inovações são realizadas principalmente nas atividades leite e aves, mostrando que as principais atividades são aquelas que mais recebem investimentos (Tabela 3). Os dados evidenciam que a principal forma de introdução de inovações tecnológicas para o grupo AI é a aquisição de equipamentos para o sistema de ordenha e automatização na produção de aves. Já o grupo BI apresenta maior diversidade quanto ao tipo de inovação, contemplando melhorias nas instalações, máquinas (tratores) e outras práticas consideradas mais simples, como, por exemplo, novos manejos para a produção de forragens para a alimentação animal.

Já os grupos NI e BI se correlacionam negativamente com a renda agrícola e pecuária (Figura 1). Neste caso, estes grupos estão associados à obtenção de rendas não agrícolas (RNA), à maior idade do produtor e ao maior número de membros que compõem a família (UTH F). Isso pode ser explicado pela redução da importância relativa das atividades agropecuárias na composição da renda total da família, ou seja, há mudança de foco do agrícola para o não agrícola. Muito embora vários estudos mostrem que o acesso às atividades não agrícolas tem proporcionado aumento da renda familiar (CARNEIRO, 2007; PERONDI, 2007; SILVA et al., 2008), neste trabalho, não se verifica a transferência desta renda para investimentos em atividades agrícolas. Neste aspecto, identifica-se a necessidade de novos estudos para verificar em que medida o acesso à RNA representa risco para a sucessão da UP ou, por outro lado, para contribuir para o ingresso de capital e estimular os investimentos em tecnologia. Outro dado que confirma a tentativa de 
explicar a não inovação é a baixa captação de financiamentos por este grupo de produtores (Tabela1).

Tabela 3 - Principais inovações tecnológicas segundo o grau de inovação das propriedades

\begin{tabular}{|l|l|l|}
\hline \multirow{2}{*}{ TIPO DE INOVAÇÃO TECNOLÓGICA } & \multicolumn{2}{|l|}{ UNIDADES DE PRODUÇÃO (\%) } \\
\cline { 2 - 3 } & BI & AI \\
\hline Equipamentos para ordenha & 9,1 & 55,6 \\
\hline Instalações para produção de leite & 15,1 & - \\
\hline Melhorias no sistema de produção de forragens & 18,2 & - \\
\hline Equipamentos para avicultura & 24,2 & 38,8 \\
\hline Instalações para avicultura & 3,0 & - \\
\hline Trator & 9,1 & - \\
\hline Instalações para Suinocultura & 6,1 & - \\
\hline Estrutura para produção de hortaliças & 6,1 & - \\
\hline Outras máquinas e equipamentos & 9,1 & 5,6 \\
\hline TOTAL & $100,0 \%$ & $100,0 \%$ \\
\hline
\end{tabular}

No que tange à mão de obra familiar (UTH familiar), ela é constituída basicamente pelo casal mais um ou dois filhos. Diferenças poderiam ser encontradas quando comparados casais jovens com casais de maior idade, porém, nos grupos avaliados, a idade média é muito semelhante, apresentando baixa variabilidade dos dados. Entretanto, a baixa inovação (BI) está associada à maior idade do gestor da UP.

Por fim, ainda de acordo com a Figura 1, as demais variáveis incluídas no modelo (crédito, internet e cooperado) não apresentaram clara relação com a inovação tecnológica nas UPs avaliadas, contudo estão fortemente associadas entre si, uma vez que o acesso aos financiamentos é facilitado pela disponibilidade de informações e auxílio na elaboração de projetos, obtidos via internet e cooperativa. Efeitos positivos para a inovação tecnológica eram esperados para estas variáveis (sobretudo 
para o crédito), no entanto, neste trabalho, esta relação não ficou suficientemente evidenciada. Parte deste resultado pode ser explicado pelo fato de o crédito obtido pelos agricultores, em grande medida, ter sido utilizado também para o financiamento dos custos de produção. Com isso, sugerem-se novos estudos empíricos para melhor análise do efeito dessas variáveis sobre a inovação, muito embora apresentassem associação com o aumento da renda de atividades pecuárias.

Um conjunto de fatores de natureza diversa, envolvendo desde aspectos de natureza macroeconômica, especificação das tecnologias, até características particulares dos agricultores familiares, parece explicar as dificuldades enfrentadas para ampliar sua base tecnológica. No presente trabalho, as principais limitações apontadas pelos agricultores foram o alto custo de implementação, para $60 \%$ dos entrevistados, seguida da disponibilidade de recursos e incertezas quanto aos resultados. Conforme destaca Knob (2006), a adoção de técnicas associadas a novas tecnologias se depara com uma grande limitação devida ao elevado custo de aquisição e implantação do sistema, nem sempre garantindo o retorno esperado, assim restringindo o uso destas tecnologias em pequenas propriedades, caso da agricultura familiar.

Os impactos das inovações tecnológicas, com exceção da redução do impacto ambiental, exercem um significativo grau de influência sobre as variáveis analisadas (Tabela 4). De maneira geral, verifica-se também que no grupo de produtores que mais inovaram (AI) as inovações impactaram de modo mais acentuado sobre as demais variáveis quando comparado com o grupo de baixa inovação (BI).

Quando se avalia a redução do tempo, do esforço físico e da mão de obra para a realização das práticas agropecuárias (tarefas), percebe-se que a influência é significativamente alta, sobretudo para o grupo AI. De acordo com Souza Filho et al. (2011), a introdução de tecnologias de base química e mecânica na agricultura resulta em substancial redução do emprego de mão de obra na produção. A indicação de alta influência para a diminuição do esforço físico e também para a melhoria 
da qualidade de vida da família está associada à redução da mão de obra e denota coerência nas respostas encontradas. Franco (2002) destaca que a melhoria da condição de vida do produtor rural está relacionada às novas tecnologias geradas. A influência mais elevada no grupo AI está diretamente associada ao tipo de inovação empregada, isto é, equipamentos destinados à automação das atividades de ordenha e das práticas de manejo na produção de frango (Tabela 3).

Tabela 4 - Grau de influência da principal inovação tecnológica empregada nas propriedades para os grupos BI e AI

\begin{tabular}{|l|l|l|l|l|l|l|}
\hline \multirow{2}{*}{ VARIÁVEIS } & \multicolumn{6}{l}{ GRAU DE INFLUÊNCIA (\%) } \\
\cline { 2 - 8 } & \multicolumn{2}{|l|}{ BI } & \multicolumn{2}{l|}{ AI } \\
\cline { 2 - 8 } & Baixa & Média & Alta & Baixa & Média & Alta \\
\hline Redução do tempo da atividade & 15,2 & 33,3 & 51,5 & 11,1 & 5,6 & 83,3 \\
\hline Redução do esforço físico & 12,1 & 33,3 & 54,5 & 11,1 & 16,7 & 72,2 \\
\hline Redução da mão de obra & 9,0 & 45,5 & 45,5 & 11,1 & 22,2 & 66,7 \\
\hline Melhoria da qualidade de vida familiar & 6,1 & 57,6 & 36,4 & 5,6 & 38,9 & 55,6 \\
\hline Melhoria da qualidade do produto & 9,1 & 24,2 & 54,5 & 11,1 & 22,2 & 66,7 \\
\hline Melhoria do bem-estar animal & 21,2 & 27,3 & 45,5 & 11,1 & 27,8 & 61,1 \\
\hline Redução do impacto ambiental & 66,7 & 27,3 & 6,1 & 88,9 & 11,1 & 0,0 \\
\hline Aumento da produtividade & 21,2 & 24,2 & 54,5 & 38,9 & 38,9 & 22,2 \\
\hline Redução dos custos de produção & 21,2 & 57,6 & 21,2 & 33,3 & 55,6 & 11,1 \\
\hline Aumento da renda da atividade & 9,1 & 69,7 & 21,2 & 11,1 & 77,8 & 11,1 \\
\hline
\end{tabular}

Consequentemente, observou-se um impacto médio/alto na qualidade de vida da família, qualidade do produto e no bem-estar animal. Bonadio et al. (2005) encontraram evidências de que o emprego de tecnologias avançadas de produção impactou diretamente na melhoria da qualidade de vida dos produtores. Resultados semelhantes também foram encontrados por Nogueira Júnior et al. (2002), evidenciando os mesmos efeitos na atividade da cotonicultura no Brasil.

A preocupação voltada ao bem-estar animal é um assunto que vem recebendo maior destaque nas discussões que envolvem a produção 
animal, e esta preocupação vem se tornando primordial quando se pensa em aumentar e aperfeiçoar a produção. Segundo Molento; Bond (2008), a valorização do bem-estar animal parte de um aumento na preocupação da sociedade em relação à qualidade de vida dos animais que são utilizados pelo ser humano.

O inverso acontece com o efeito esperado sobre as questões ambientais, em que as tecnologias empregadas apresentam baixa influência na redução do impacto ambiental das atividades agropecuárias. Segundo Bin; Paulino (2004), a partir da década de 80, e com maior ênfase, a partir da década de 90, ampliou-se, em âmbito mundial, o debate acerca das relações entre meio ambiente e o desenvolvimento científico e tecnológico. Apesar de a preocupação com a questão ambiental vir de longa data, Vello (2009) observou no estado do Paraná grande dificuldade de inovações tecnológicas objetivando a implementação de novas formas de cultivo mais sustentáveis, principalmente nas regiões onde predominam as monoculturas. Apesar deste comportamento, Palhares (2010) destaca que novos índices adquirem cada vez mais importância na produção zootécnica, tais como a quantidade de resíduos gerados, concentração dos gases emitidos eeficiência hídrica.

No que tange aos ganhos de produtividade, os dados revelam um impacto mais positivo no grupo BI do que para o AI. No grupo BI, os tipos de inovações incorporadas (Tabela 3 ) têm foco mais direto sobre os sistemas de produção, tais como as melhorias na produção de alimentos e estrutura física, com impactos diretos sobre os ganhos de produtividade; enquanto no grupo AI, as inovações se concentram na automação de algumas atividades do processo produtivo, como, por exemplo, na ordenha e resfriamento do leite, cujos efeitos sobre a produtividade dos animais é nulo.

Estudos como os de Kageyama (2003) demonstram que a adoção de tecnologia revelou estar correlacionada com o aumento na produtividade das propriedades rurais. Considerando diferentes atividades agropecuárias, existem na literatura vários estudos que identificam que a adoção de novas tecnologias pelos agricultores resulta em elevação na produtividade 
e na renda das propriedades rurais. Como exemplo, o aumento da produtividade da cultura do feijão foi verificado por Silveira et al. (2001), e maiores níveis de produtividade na atividade leiteira de algumas regiões de Minas Gerais foram constatados por Galinari et al. (2002).

O grau de influência sobre a redução dos custos de produção foi classificado, preponderantemente, como médio para os dois grupos avaliados. A diminuição dos custos de produção pela adoção de novas tecnologias pode ser observada em diversas regiões do país, caso de estudos realizados por Franco (2002), em que a introdução de inovações tecnológicas contribuiu com uma redução de $55 \%$ nos custos de produção quando do manejo integrado de plantas daninhas na região do estado da Paraíba.

Por fim, as inovações exercem média influência sobre o aumento da renda, em decorrência do impacto verificado sobre a produtividade e custos de produção. Isso pode ser explicado com base no que destaca Silva (1995), em que os benefícios da inovação tecnológica que ocorrem nos produtos agrícolas não são distribuídos de forma equitativa entre os agentes econômicos. Agricultores que têm uma melhor estrutura de produção (maior capital de investimento, maquinários e terras) poderão produzir em maior escala, com melhores resultados em termos quantitativos e qualitativos Desta maneira, obterão melhores retornos advindos da produção, em decorrência da economia de escala e de melhores preços.

\section{Conclusões}

As inovações tecnológicas estão intimamente relacionadas com a posse da terra e capital. Os gestores com maior escolaridade usufruem de financiamentos para ampliar seus investimentos, que ocorrem principalmente em máquinas, equipamentos e construções, gerando um círculo virtuoso entre capital e inovações tecnológicas. 
O emprego de inovações tecnológicas impacta positivamente sobre os indicadores de produção e dos produtos gerados, com reflexos positivos sobre a qualidade de vida e a renda familiar. Contudo, a preocupação com questões ambientais assume caráter secundário.

Se por um lado as rendas não agrícolas são oportunidades para melhoria da renda familiar, por outro, sinalizam para a existência de outra estratégia de reprodução familiar que necessita ser investigada, uma vez que a não inovação pode, no longo prazo, comprometer a sustentabilidade econômica dos sistemas produtivos agropecuários.

\section{Referências}

BARROS, G. S. de C. A agricultura brasileira: desempenho, desafios e perspectivas. Política agrícola no Brasil: subsídios e investimentos. GASQUES, J. G.; FILHO, J. E. R. V.; NAVARRO, Z. (Org.). Brasília: Ipea, 2010. 294 p.

BIN, A.; PAULINO, S. R. Inovação e meio ambiente na pesquisa agrícola. In: ENCONTRO ANUAL DA ASSOCIAÇÃO NACIONAL DE PÓSGRADUAÇÃO E PESQUISA EM AMBIENTE E SOCIEDADE, 2., 2004, Indaiatuba/SP. Anais... Indaiatuba: ANPPAS, 2004.

BONADIO, L. F.; TUPY, O.; RODRIGUES, G. S.; RODRIGUES, I. A.; CAMARGO, A. C. Impactos social de inovações tecnológicas na agricultura familiar: tecnologias para produção de leite. In: CONGRESSO DA SOCIEDADE BRASILEIRA DE ECONOMIA E SOCIOLOGIA RURAL, 43., 2005, Ribeirão Preto. Anais... Ribeirão Preto: SOBER, 2005.

CARNEIRO, W. M. A. Política pública e renda na agricultura familiar: a influência do Polo de Desenvolvimento de Agronegócios Cariri Cearense. In: CONGRESSO DA SOCIEDADE BRASILEIRA DE ECONOMIA E SOCIOLOGIA RURAL, 45., 2007, Londrina. Anais...Londrina: SOBER, 2007. 
COCHRANE, W. W. Farm price: myth or reality. Minneapolis: University of Minnesota Press, 1958.

CONTERATO, M. A.; FERNANDES, L. L.; LIBARDONI, P. J.; GOMES, M. C.; STEIN, A. de Q. Evolução da agropecuária brasileira: eficiência e produtividade na vanguarda de um modelo de desenvolvimento rural. In: CONGRESSO DA SOCIEDADE BRASILEIRA DE ECONOMIA E SOCIOLOGIA RURAL, 50., 2012, Vitória. Anais...Vitória: SOBER, 2012.

ELLIS, F. Rural livelihoods and diversity in developing countries. Oxford: Oxford University Press, 2000. 273p.

FRANCO, C.F. de O. Dinâmica da difusão de tecnologia no sistema produtivo da agricultura brasileira. In: SIMPÓSIO NACIONAL SOBRE AS CULTURAS DO INHAME E DO TARO, 2., 2002, João Pessoa, PB. Anais... João Pessoa: Emepa-PB, 2002.

GALINARI, R.; CAMPOS, B.; LEMOS, M. B.; SANTOS, F. BIAZI, E. Tecnologia, especialização regional e produtividade: um estudo da pecuária leiteira em Minas Gerais. In: SEMINÁRIO SOBRE A ECONOMIA MINEIRA, 10., 2002, Diamantina. Anais... DiamantinaMG, 2002.

GUANZIROLI, C. E. Pronaf dez anos depois: resultados e perspectivas para o desenvolvimento rural. In: ENCONTRO NACIONAL DE ECONOMIA, 34., 2006, Salvador. Anais...Salvador: ANPEC, 2006.

IBGE - Instituto Brasileiro de Geografia e Estatística. Banco de dados. Disponível em: <http://www.ibge.gov.br> Acesso em: 29jan. 2013.

KAGEYAMA, A. Produtividade e renda na agricultura familiar: efeitos do PRONAF-crédito. Agricultura em São Paulo, v. 50, n. 2, p. 1-13, 2003. 
KNOB, M. J. Aplicação de técnicas de agricultura de precisão em pequenas propriedades. $129 \mathrm{f}$. Dissertação (Mestrado) - Centro de Ciências Rurais, Universidade Federal de Santa Maria, Santa Maria. 2006.

LEPS, J.; SMILAUER, P. Multivariate analysis of ecological data using CANOCO.Ceské Budejovice: University of South Bohemia, 1999.

LIMA, A. P. de et al. Administração da unidade de produção familiar: modalidades de trabalho com agricultores. Ijuí: UNIJUÍ, 2001.

MATTEI, L. Impactos do pronaf: análise de indicadores. Brasília: MDA, 2005. 136 p.

MATTAR, F.N. Pesquisa de marketing. São Paulo: Atlas, 2001.

MINAYO, M. C. de S. O desafio da pesquisa social. In: DESLANDES, S. F.; GOMES, R.; MINAYO, M. C. de S. (Org.) Pesquisa social: teoria, método e criatividade. 27 ed. Rio de Janeiro: Vozes, 2008, p. 9-29.

MOLENTO, C. F. M.; BOND, G. B. Produção e bem-estar animal: aspectos éticos e técnicos da produção de bovinos. Ciência Veterinária nos Trópicos, Recife-PE, v. 11, suplemento 1, p. 36-42, 2008.

NEY, M. G.; HOFFMANN, R. Origem familiar e desigualdade de renda na agricultura. Pesquisa e planejamento econômico, v. 33, n. 3, p. 541-572, 2003.

NOGUEIRA JÚNIOR, S.; BARBOSA, M. Z.; FERREIRA, C. R. R. P. T. Tecnologia e produtividade da cotonicultura brasileira. Agricultura em São Paulo, v. 49, n. 2, p. 17-29, 2002.

PALHARES, J. C. P. Impacto ambiental das produções animais. Concórdia: Embrapa Suínos e Aves, 2010. 
PEREIRA, S.; FIGUEIREDO, A.; LOUREIRO, R. Avaliação da política de agricultura familiar: uma abordagem de efeito-fixo.In: CONGRESSO DA SOCIEDADE BRASILEIRA DE ECONOMIA E SOCIOLOGIA RURAL, 42., 2004, Cuiabá. Anais...Cuiabá: SOBER, 2004.

PERONDI, M. A. Diversificação dos meios de vida e mercantilização da agricultura familiar. $224 \mathrm{f}$. Tese (Doutorado em Desenvolvimento Rural) - Programa de Pós-Graduação em Desenvolvimento Rural Universidade Federal do Rio Grande do Sul, Porto Alegre, 2007.

SILVA, C. da; SIMIONI, F. J.; PRETTO, F. N.; TALAMINI, E. Análise da rentabilidade de pequenas propriedades rurais. In: ENCONTRO NACIONAL DA ANPAD, 32., 2008, Rio de Janeiro. Anais ... Rio de Janeiro: ANPAD, 2008.

SILVA, C. R. L. da. Inovação tecnológica e distribuição de renda: impacto distributivo dos ganhos de produtividade da agricultura brasileira. São Paulo: IEA, 1995. 25 p. (Coleção Estudos Agrícolas, 21).

SILVEIRA, P. M.; SILVA, O. F.; STONE, L. F.; SILVA, J. G. Efeitos do preparo do solo, plantio direto e de rotações de culturas sobre o rendimento e a economicidade do feijoeiro irrigado. Pesquisa Agropecuária Brasileira, v. 36, n. 2, p. 257-63, 2001.

SOLDATELLI, D. Margem bruta, lucro e outros índices. In: SEMANA DE ATUALIZAÇÃO EM ADMINSTRAÇÃO RURAL, 1991, Lages. Anais... Florianópolis: SAA/EPAGRI, 1992. p. 27-47.

SOUZA FILHO, H. M. de; BUAINAIN, A. M.; SILVEIRA, J. M. F. da; VINHOLIS, M. de M. B. Condicionantes da adoção de inovações tecnológicas na agricultura. Cadernos de Ciência \& Tecnologia, Brasília, v. 28, n. 1, p. 223-255, jan./abr. 2011.

SILVA, F. C. A.; HEIDEN, F. C.; AGUIAR, V. V. P.; PAUL, J. M. Migração rural e estrutura agrária no oeste catarinense. Florianópolis: Instituto Cepa/SC, 2003. 99 p. 
TER BRAAK, C. J. F.; SMILAEUR, P. Reference manual and user's guide to canoco for windows: Software for Canonical Community Ordination (version 4), Ithaca, New York, USA, Microcomputer Power. 1998. $500 \mathrm{p}$.

VEIGA, J. E. da. Uma linha estratégica de desenvolvimento agrícola. Revista de Economia Política, v. 12, n. 2, p. 88-115, 1992.

VELLO, M. As inovações tecnológicas na produção agrícola do estado do Paraná e sua relação com o desafio da sustentabilidade econômica e ambiental. 154 f. Dissertação (Mestrado) - FAE Centro Universitário, Curitiba. 2009. 